\title{
ANTENNAL SENSILLA OF MAGICICADA CASSINI (FISHER) (HOMOPTERA : CICADIDAE): FINE STRUCTURE AND ELECTROPHYSIOLOGICAL EVIDENCE FOR OLFACTION
}

\author{
Ulla Klein*市, Cornelia Bock*, Wolf A. KafKa* and Thomas E. Moore $\dagger$ \\ *Max-Planck-Institut für Verhaltensphysiologie, D-8131 Seewiesen, F.R.G.; \\ †useum of Zoology, The University of Michigan, Ann Arbor, Michigan 48109-1079, U.S.A.
}

(Accepted 23 October 1987)

\begin{abstract}
The antennae of Magicicada cassini (Homoptera : Cicadidae) (3-4 mm long) look similar in both sexes and consist of scape, pedicel, and a 5-segmented flagellum. The length of flagellar segment 1 varies independently in relation to head size and is slightly longer in females $(0.96 \mathrm{~mm})$ than in males $(0.89 \mathrm{~mm})$. The ventral side of flagellar segment 1 is covered with sensilla coeloconica comprising about 60 large, 10 mediumsized, and 35 small sensilla with pit diameters of $8-24,6-10$, and $2 \mu \mathrm{m}$, respectively. The large and the medium-sized sensilla coeloconica are multiporous single-walled sensilla with pore tubules, containing branched entangled dendrites from 3 receptor cells. The small sensilla coeloconica, situated primarily at the outer border of the sensillum field, are no-pore sensilla with inflexible sockets. They contain 2 unbranched dendrites extending to the tip of the peg, and 1 dendrite reaching to its base and wrapping around the other 2 dendrites. Small sensilla campaniformia (cap diameter $3 \mu \mathrm{m}$ ) are aligned at the outer border of the sensillum field and continue all along the flagellum. Up to 3 olfactory receptor cells were distinguished on the basis of their nerve impulse amplitudes through extracellular electrophysiological recordings from sensilla coeloconica, presumably large ones. They respond to stimulation by cyclic terpenoids with different but highly overlapping reaction spectra, and react selectively to structural variations of the molecules. No responses to $\mathrm{CO}_{2}$, temperature or moisture were recorded.
\end{abstract}

Index descriptors (in addition to those in title): Periodical cicadas, chemoreceptors, insect-host plant relationship, transmission electron microscopy, scanning electron microscopy.

\section{INTRODUCTION}

PERIOdical cicadas (Magicicada spp.) appear as adults for only 4-6 weeks after a subterranean development of 13 or $17 \mathrm{yr}$ in 15 different geographical populations ("broods") in different years in large areas from the northeastern to the midwestern part of the United States (Alexander and Moore, 1958, 1962; Lloyd and Dybas, 1966a, b; Lloyd, 1984). In most places and in most years, an emergence is precisely synchronized among 3 intermingled species (Alexander and Moore, 1962; Hoppensteadt and Keller, 1976). Periodical cicadas apparently cannot reproduce successfully without forming huge dense populations (Alexander and Moore, 1962; Karban, 1982).

‡ Present address: Zoologisches Institut der Universität, Luisenstr. 14, D-8000 München 2, F.R.G. 
Periodical cicadas are said not to be very specific concerning the plants upon which they suck xylem sap or oviposit. Broadly overlapping habitat preferences among the 3 species are suggested by Dybas and Lloyd $(1962,1974)$. White $(1980)$ concludes that the ovipositional patterns on the different host plants she observed can best be explained by inherited general criteria for host plant preference, not necessarily species-specific. Maier (1982) reported for $M$. septendecim a discrimination of host plants dependent on behavioral context: 49 plant species were accepted for ovipositing but only 33 of them for feeding.

It seems apparent that cicadas discriminate host plants and habitats, and it seems likely that chemical signals are involved at least in host plant selection. Despite the many investigations of the striking acoustical and visual congregational behavior of Magicicada, nothing is known about their chemical senses. The first morphological survey of possible chemosensory structures was carried out on the antenna, beak, and ovipositor of $M$. cassini using scanning electron microscopy (Klein et al., 1987). Drawbacks for physiological investigations of these animals, even though they appear in huge numbers, are that their adult life span is very short and they need live plants for feeding approximately every $2 \mathrm{hr}$.

This paper presents a description of the antennal sensilla, especially sensilla coeloconica on flagellar segment 1 , with emphasis on their possible role in olfaction. The morphological investigation was performed by scanning and transmission electron microscopy. The olfactory function was tested by electrophysiological measurements (extracellular single cell recordings). The chemical stimuli were chosen to allow first conclusions on the specializations of these receptor cells to naturally occurring compounds.

\section{MATERIALS AND METHODS}

Adult males and females of $M$. cassini (Fisher) were collected in Jackson County, Missouri, 1981 (brood IV), in Hocking County, Ohio, 1982 (brood V), in Beaver County, Pennsylvania, 1985 (brood VIII), and in Mercer County, West Virginia, 1986 (brood IX).

\section{Scanning electron microscopy}

Some antennae were air-dried directly after dissection, others were fixed in a mixture modified after Carnoy (glacial acetic acid / chloroform / absolute ethanol =1:1:3), dehydrated in ethanol and either air-dried after immersion in hexamethyldisilazane (HMDS, Merck) for 5 min according to Bock (1987) or subjected to critical-point drying according to Hayat (1978). All specimens were mounted on aluminium stubs by doublesided sticky tape, sputtered with gold, and inspected at $15 \mathrm{kV}$ in a Zeiss scanning electron microscope (Novascan 30).

\section{Transmission electron microscopy}

Flagellar segments 1 were cut from antennae of both sexes, fixed at $4^{\circ} \mathrm{C}$ for $4 \mathrm{hr}$ in $2.5 \%$ glutaraldehyde with

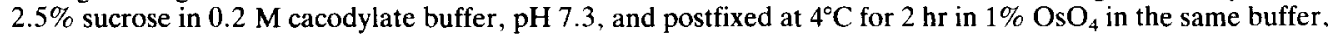
dehydrated in graded ethanol series, and transferred over propylene oxide in Spurr's medium for embedding. Serial ultrathin sections were made on a Reichert Microtome Ultracut OMU3 with a diamond knife, double stained in uranyl acetate and lead citrate, and examined in a Zeiss transmission electron microscope (EM 10A).

\section{Electrophysiological recordings}

Intact animals were mounted dorsally and their antennae fixed on sticky tape or sticky wax to present the sensilla coeloconica on the ventral side of the antenna. Recordings were made from single sensilla by touching the cuticular surface of a peg in the pit of the sensilla at an angle of about $40^{\circ}$ from distal with the tip of the glass capillary electrode filled with $3 \mathrm{M} \mathrm{LiCl}$. The indifferent electrode, an $\mathrm{Ag} / \mathrm{AgCl}_{2}$ wire, was inserted into the thorax. Nerve impulses were recorded extracellularly by standard methods (Kafka, 1970) (AC;3-20 KHz bandpass; input resistance $10 \mathrm{MOhm}$; amplification $\times 10$ ) and stored with a Racal 4-channel tape recorder at 
$7.5 \mathrm{in} / \mathrm{sec}$. The response rates were evaluated on paper prints by counting the impulse frequencies during stimulation (the spontaneous activity was less than $1 \mathrm{~Hz}$ ). During experiments, the preparations were exposed to a constant air stream directed onto the antenna (about $1 \mathrm{~m} / \mathrm{sec}$ ), saturated by water vapor and kept at about $20^{\circ} \mathrm{C}$, to minimize contamination and to prevent drying.

The 50 test compounds comprised homologous aliphatic and cyclic compounds varying in their degrees of saturation and structural modifications (aldehydes, alcohols, acids, esters, ketones, hydrocarbons; cf. Table 1). They were kept undiluted in small bottles (volume $2 \mathrm{ml}$ ). For stimulation, the openings were held into the constant air stream for $2 \mathrm{sec}$ at intervals up to $1 \mathrm{~min}$ (Kafka, 1970). Vapor pressures ("Vap" in Table 1) were calculated according to the boiling points (Kafka, 1987). The stimulus substances were not tested in a particular order, but a few compounds were tested repetitively for reference. Sensitivity for $\mathrm{CO}_{2}$ was tested simply by breathing onto the preparation, heat sensitivity by drawing a heated soldering iron near the antenna, and sensitivity for moisture by varying the constant air stream between a dry and a water-vapor-saturated stream.

\section{RESULTS}

\section{Gross morphology of the antenna}

Each antenna inserts in an antennal fovea of the cranium at the side of the postclypeus near an anterior tentorial pit (Snodgrass, 1927; Kramer, 1950; Figs 1; 3a, b). They are about 3-4 mm long and consist of a scape, a pedicel, and a 5-segmented distally tapering flagellum. Only the connections among scape, pedicel, and flagellar segment 1 are articulated. The slight constrictions of the cuticle between the distal segments are defined as segmental boundaries even though they lack clear sutures (Fig. 1). The typical posture of the antenna is straight forward with the distal segments bent slightly outward (Figs 1; $3 a$ ). The scape ( $\approx 0.6 \mathrm{~mm}$ long) is partially concealed in the antennal fovea and dorsally covered by the overhanging ridge of the vertex (Figs $1 ; 3 \mathrm{a} ; 4)$. The curved pedicel $(\approx 0.6$ $\mathrm{mm}$ long) is the only segment that appeared light brown compared with all the others that are dark black. Flagellar segments 2,3 , and $4(\approx 0.7,0.6$, and $0.3 \mathrm{~mm}$ long, respectively) are slightly curved. The apical tip of flagellar segment $5(\approx 0.2 \mathrm{~mm}$ long $)$ is characterized by a finger-like, somewhat laterally compressed protrusion $(\approx 50 \mu \mathrm{m}$ long; Figs 1; 2).

Flagellar segment 1 tapers to a subapical neck, is slightly swollen in the middle, and necked near the base (Figs $1 ; 11$ ). The subapical neck and the swelling are more prominent in specimens of broods IV, V and VIII, especially in males, than of brood IX. Measurements in brood IX revealed that flagellar segment 1 is only slightly longer in

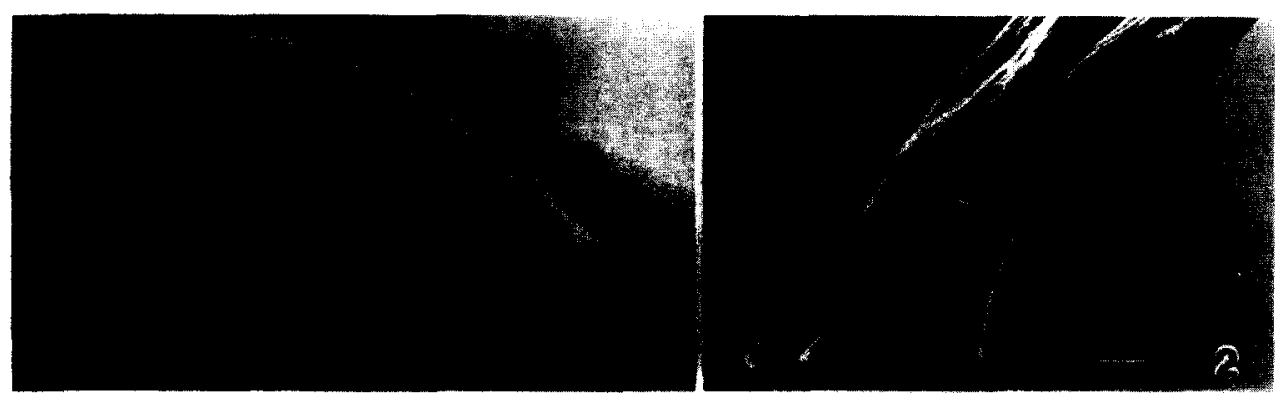

Fig. 1. Right antenna of a male Magicicada cassini, seen from frontal plane, overview. Scanning electron micrograph. Segments are numbered from proximal to distal. Sc $=$ scape; $\mathrm{Pe}=$ pedicel. Arrow points to ventrolateral position of sensillum field. Bar $=200 \mu \mathrm{m}$.

Fig. 2. Apex of flagellar segment 5 of antenna of $M$. cassini. Scanning electron micrograph. Cuticular protrusion and lateral bristles. Bar $=20 \mu \mathrm{m}$. 


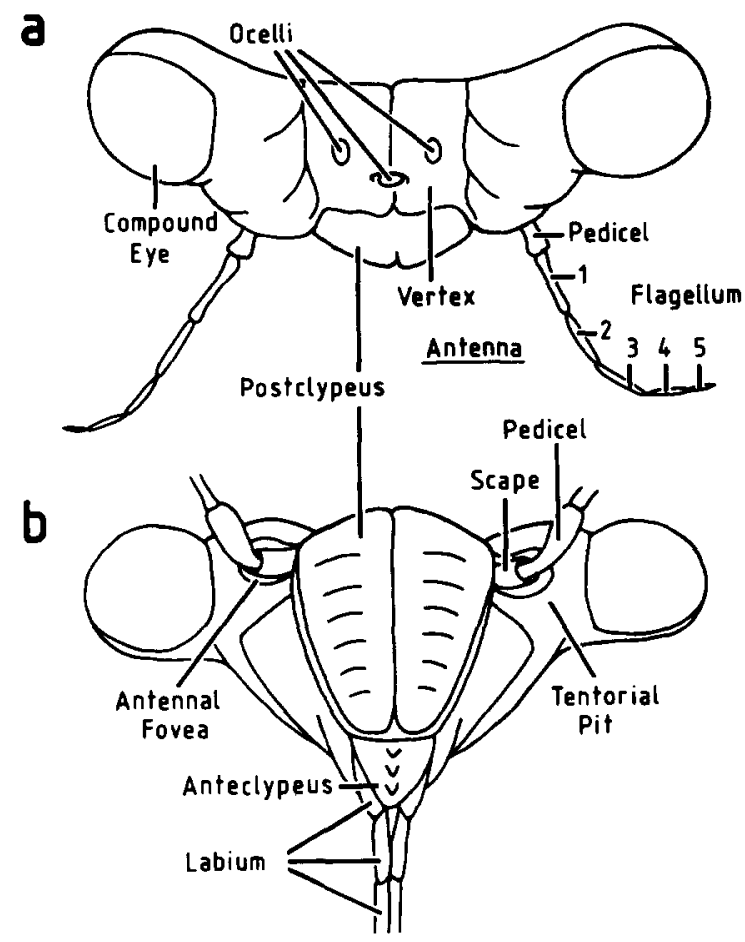

FIg. 3. Position and insertion of antennae on head of $\boldsymbol{M}$. cassini. Schematic drawings. a. Dorsal view. In this plane, the antennae are bent slightly outward at the distal segments. b. Frontal view.

females (mean and standard deviation $0.96 \mathrm{~mm} \pm 0.06, n=16)$ than in males $(0.89 \mathrm{~mm}$ $\pm 0.04, n=12$ ). Head size differs more obviously between the sexes: the vertex width is $4.2 \mathrm{~mm} \pm 0.17$ in females and $3.8 \mathrm{~mm} \pm 0.17$ in males. The length of flagellar segment 1 in each sex varies essentially independently in relation to head size (Fig. 10).

The cuticular surfaces of scape, pedicel and flagellar segments 1 and 2 are characterized by a hexagonal scale-like pattern (roofing tiles; Figs $11 ; 12$ ). The 3 distal flagellar segments, in some cases 4 segments, appear shriveled and, therefore, seem to have softer cuticle (Figs $1 ; 2$ ). This feature is independent of fixation methods and is common in young live adults in nature.

\section{Distribution of the sensilla}

On the ventrolateral side of the scape, and all around the pedicel, many stout, pointed hair sensilla are situated, mostly inclined in the direction of the long axis of the segment: a few are $\approx 400 \mu \mathrm{m}$ long, others range from 50 to $250 \mu \mathrm{m}$ (Fig. 4). On the dorsal surface of the scape some smaller sensilla lie almost plane to the surface (Fig. 4, arrows). Single hair sensilla on the pedicel are small (30-40 $\mathrm{mm}$ long), blunt and almost upright (Fig. 5). At the distal margin of both proximal antennal segments sensilla campaniformia are found (cap diameter $\approx 5 \mu \mathrm{m}$ ); smaller s. campaniformia (cap diameter $\approx 2 \mu \mathrm{m}$ ) and rimmed pores (rim diameter $\approx 6 \mu \mathrm{m}$ ) are scattered over the ventral surface (Figs 7; 8); small pores without rims (pore diameter $1-5 \mu \mathrm{m}$ ) and small plates (plate diameter $\approx 7$ $\mu \mathrm{m}$ ) with tiny knobs (Fig. 9) are other typical features. 


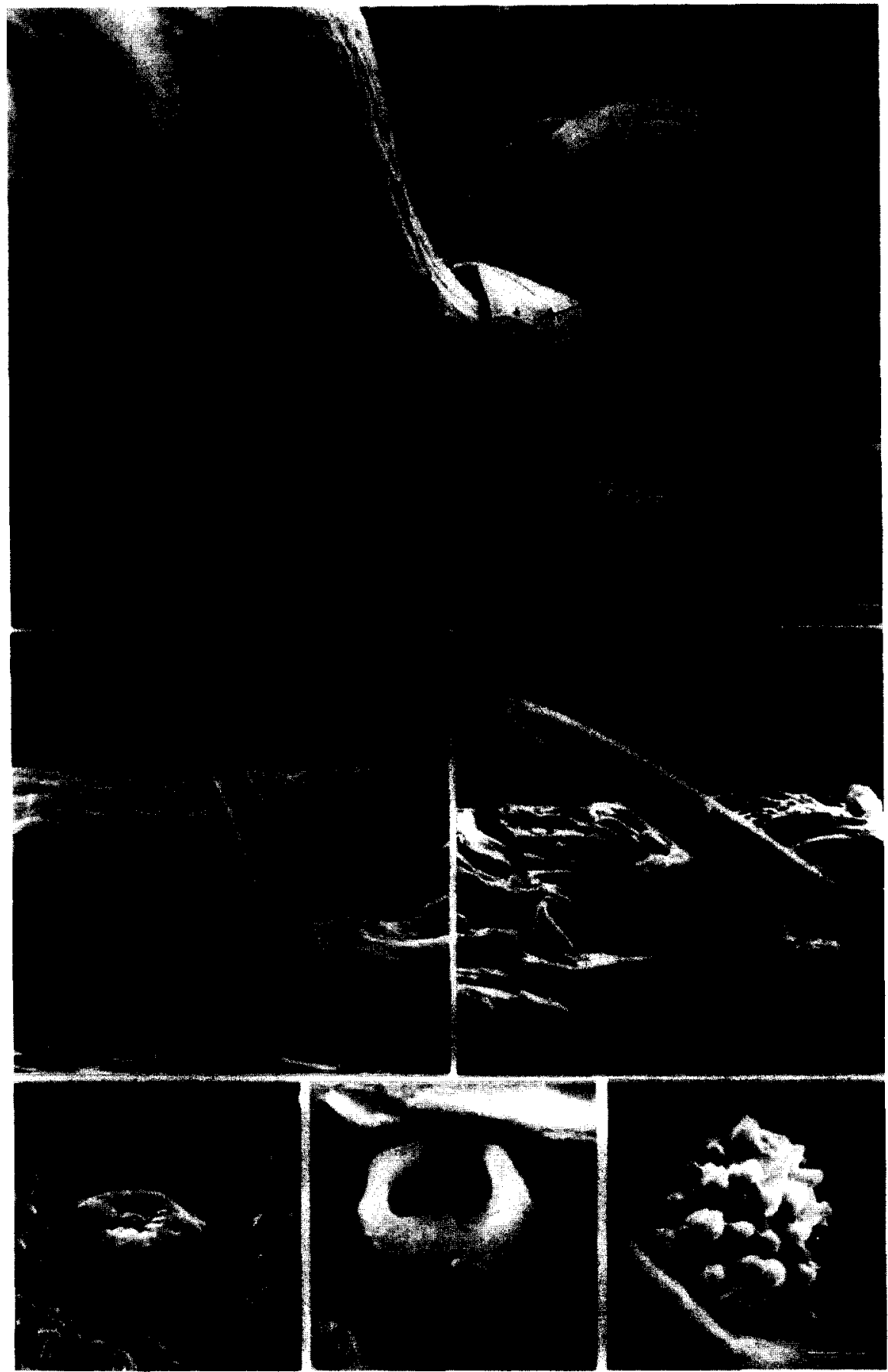

FIgs 4-9. Proximal antennal segments of $M$. cassini. Scanning electron micrographs.

FIG. 4. Scape ( $\mathrm{Sc}$ ) and pedicel ( $\mathrm{Pe}$ ) with ridge of vertex (Ve). Arrows: examples of sensilla lying in plane to surface of scape. Bar $=100 \mu \mathrm{m}$.

FIG. 5. Upright sensillum on pedicel. Bar $=10 \mu \mathrm{m}$.

FIG. 6. Bristle on segment 2 of antennal flagellum. Bar $=4 \mu \mathrm{m}$.

Fig. 7. S. campaniforme on scape. Bar $=2 \mu \mathrm{m}$.

Frg. 8. Rimmed pore on ventral side of pedicel. Bar $=2 \mu \mathrm{m}$.

FIG. 9. Knob-plate on ventral side of pedicel. Bar $=2 \mu \mathrm{m}$. 


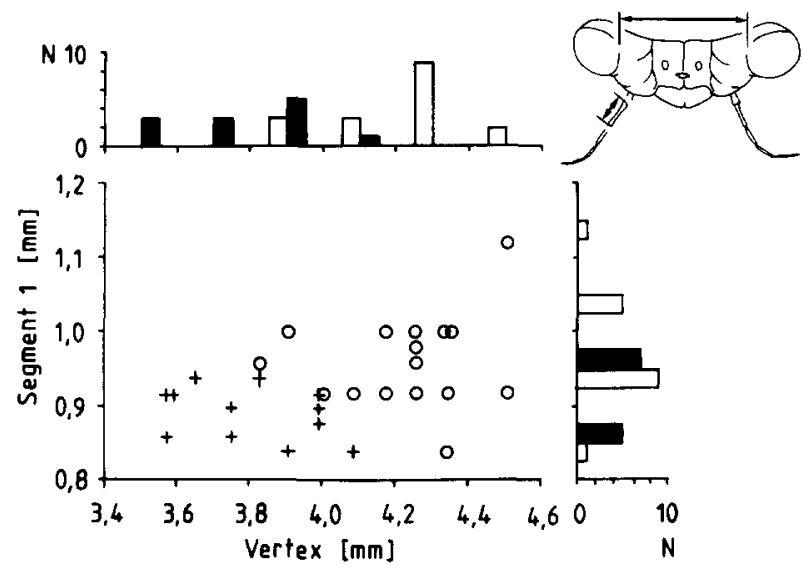

FIg. 10. Morphometry of head proportions of $M$. cassini. For each animal, length of segment 1 of the antennal flagellum is plotted against corresponding head size (vertex width); positions of the 2 distances measured are depicted in scheme of head (inset at upper right corner); $+=$ males $(n=12)$; $O=$ females $(n=16)$. Above, frequency distribution of vertex width; at the right, distribution of length of segment 1 ; black columns $=$ males; white columns $=$ females.

Flagellar segment 1 is provided with a field of sensilla on the ventrolateral side (Figs 1 ; 11). It consists of a large number of sensilla coeloconica (Figs 11 ; 12) grouped in 3 classes according to the size of the pit and the size and position of the peg. This grouping is more typical of specimens of broods V and VIII than of brood IX. Fifty to sixty-five large s. coeloconica (based on antennae from 3 males and 2 females) were characterized by average pit diameters of $15 \mu \mathrm{m}$, ranging from 8 to $20 \mu \mathrm{m}$, with blunt pegs clearly visible (Figs 11-13). Peg diameters (average $5 \mu \mathrm{m}$, ranging from 4 to $7 \mu \mathrm{m}$ ) are more constant than pit diameters. The tips of pegs vary in shape and are often asymmetrically flattened. All pegs are inclined distad, but with varying angles. In about 10 medium-sized s. coeloconica (pit diameter 6-10 $\mu \mathrm{m}$, peg diameter $2-3 \mu \mathrm{m}$ ), the pegs stand almost at right angles and are recessed below the cuticular surface (Fig. 13). Several pits of the large and medium-sized s. coeloconica contain 2-4 pegs (Fig. 11, arrows; Fig. 12). About 35 small s. coeloconica (pit diameter 1-2 $\mu \mathrm{m}$, peg diameter $<1 \mu \mathrm{m}$ ) are situated laterally at the outer border of the sensillum field, pointing outward (Figs 11; 12).

Flagellar segment 2 bears only a few large s. coeloconica (Fig. 13) facing the same side as the sensillum field on segment 1 . Sometimes a single, very long, stout, pointed bristle (up to $160 \mu \mathrm{m}$ ) with a flexible socket can be found in the middle or proximally on segment 2 , or apically on segment 4 . In some cases, a few short but stout and blunt sensilla are found on segment 2, facing outward on the lateral side of the antenna (Fig. 6 ); these bristles are found mainly in males. We do not know if these variations are typical of different broods or just of individuals. Flagellar segment 5 bears 2 long bristles (100 $\mu \mathrm{m}$ long) facing the inner and outer side of the antenna lateral to the finger-like apical elongation (Fig. 2), with a distinct socket and an ecdysial pore at the base. All flagellar segments bear a few small s. coeloconica and small s. campaniformia (cap diameter $1-2 \mu \mathrm{m}$ ). The latter are more numerous on segment 1 , and are positioned at an almost straight line laterally outward. Segment 1 has 4 slightly larger s. campaniformia around its apical border. 


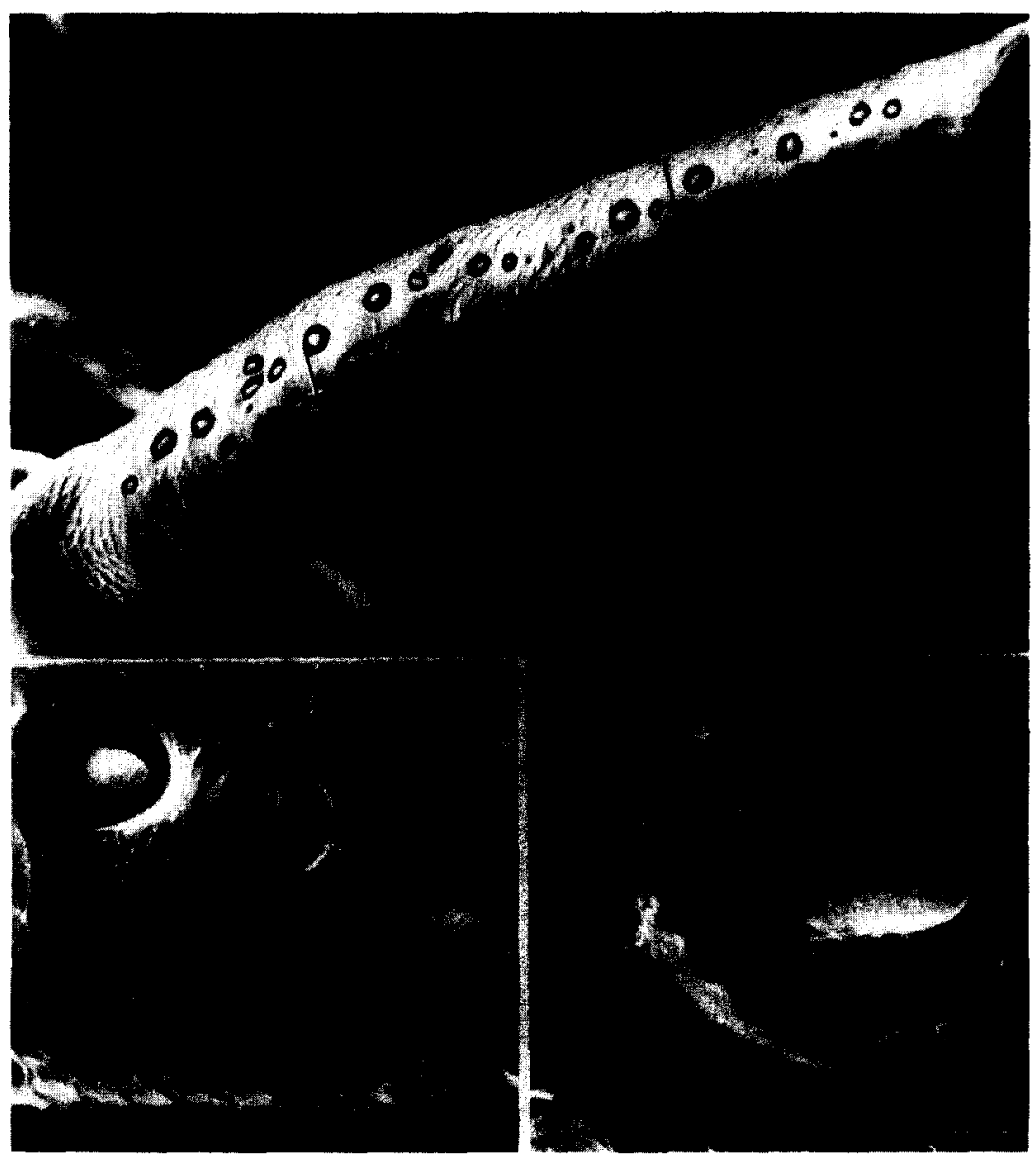

FIGS 11-13. Sensilla coeloconica on flagellar antennal segment of $M$. cassini. Scanning electron micrographs.

FIG. 11. Flagellar segment 1 with sensillum field directed ventrolaterally, male; overview. Arrows point to multiple pegs enclosed in one pit. Bar $=40 \mu \mathrm{m}$.

FIG. 12. Types of s. coeloconica on flagellar segment $1: L=$ large, $M=$ medium-sized, $S=$ small. Bar $=10 \mu \mathrm{m}$.

Fig. 13. S. coeloconicum on flagellar segment 2 with ecdysial pore (arrow). $\mathrm{Bar}=4 \mu \mathrm{m}$.

\section{The fine structure of the sensilla on flagellar segment 1}

The epidermal layer of flagellar segment 1 is very thin $(0.1 \mu \mathrm{m})$; at the side of the sensillum field it reaches a thickness of 15-20 $\mu \mathrm{m}$ (Fig. 14). The large s. coeloconica (Figs 15-17) are multiporous single-walled sensilla with pore tubules. An ecdysial pore is found at one side of the peg at about the height of the rim of the pit (Fig. 13). The sensilla contain 3 receptor cells with their dendrites highly branched and entangled inside the peg. Below the level of the peg, the dendritic segments are surrounded by a folded dendritic sheath that sometimes separates the dendrites almost completely (Fig. 17). In case of multiple pegs, the sets of dendrites are enclosed in one lumen by the foldings of one dendritic sheath only. 


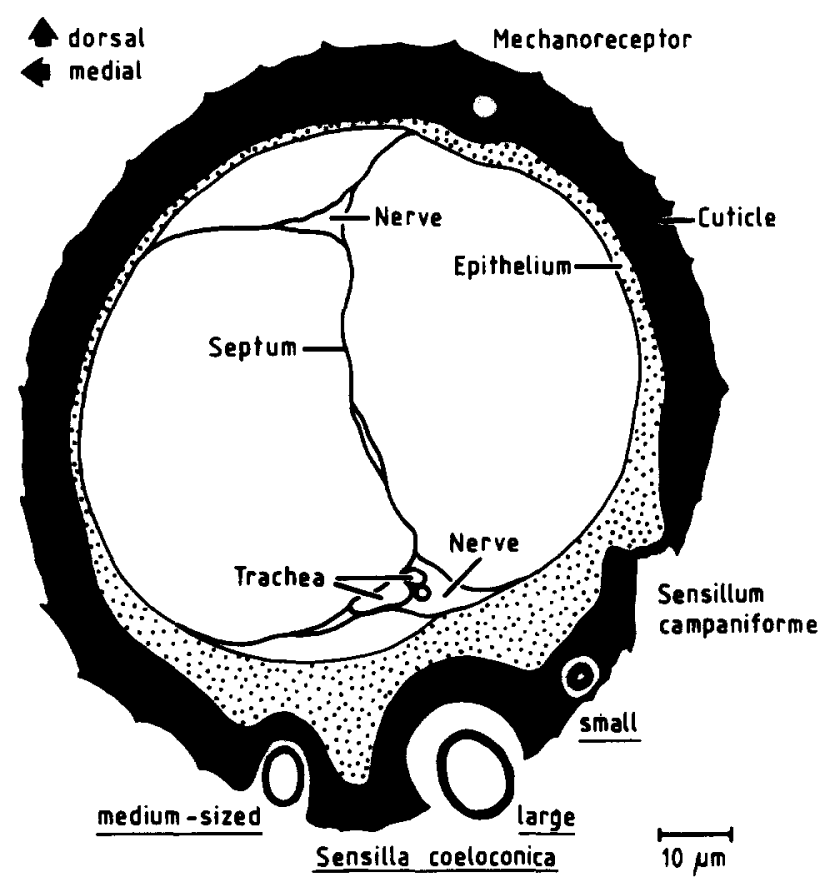

Fig. 14. Transverse section of flagellar segment 1; schematic drawing from transmission electron micrographs. Relative positions of different types of sensilla are shown.
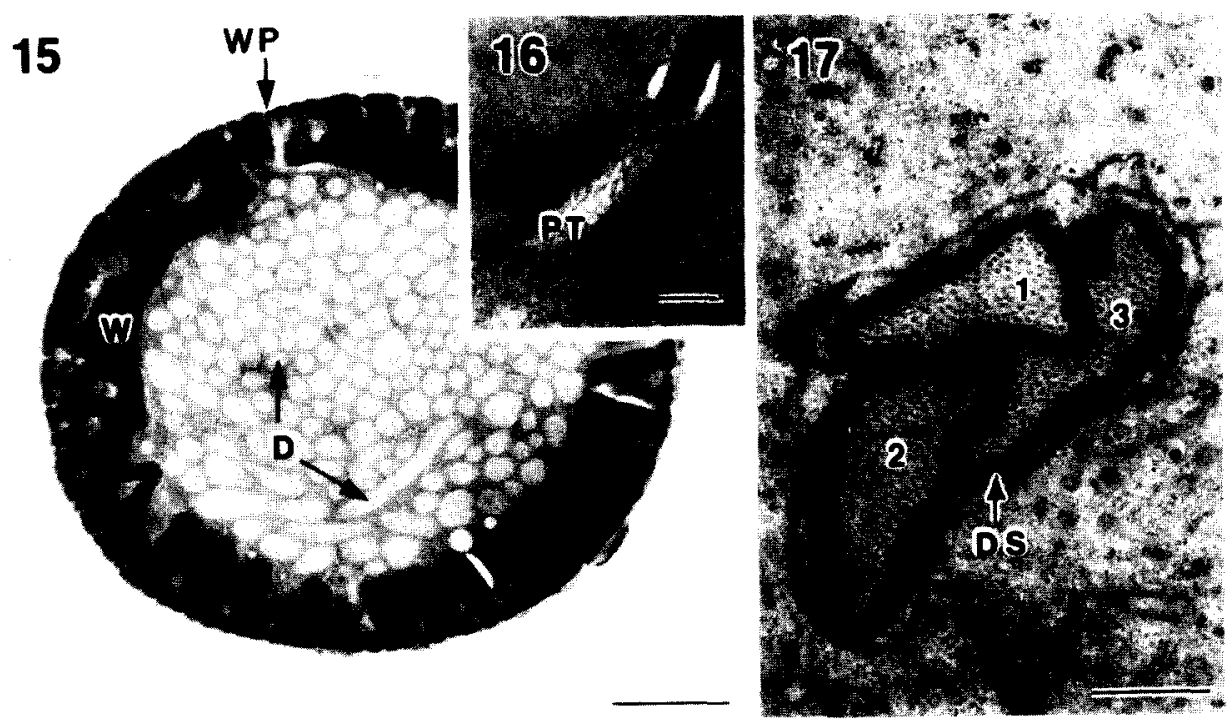

Figs 15-17. Large sensillum coeloconicum on flagellar segment 1 of $M$. cassini. Transmission electron micrographs. $\mathrm{D}=$ dendritic branches; $\mathrm{DS}=$ dendritic sheath; $\mathrm{W}=$ hair wall; $\mathrm{WP}=$ wall pore; $\mathbf{P T}=$ pore tubules; $1,2,3=$ dendrites of receptor cells $1,2,3$.

FIG. 15. Transverse section of peg with wall pores. $\mathrm{Bar}=1 \mu \mathrm{m}$.

Fig. 16. Detail of wall pore with pore tubules. Bar $=0.2 \mu \mathrm{m}$.

Fig. 17. Cross-section of dendritic sheath inside epidermis below peg, in the example shown separating the 3 dendrites by its infoldings. Bar $=0.5 \mu \mathrm{m}$. 
The medium-sized s. coeloconica (Figs 18;19) are similar to the large ones concerning the wall pores, the pore tubules and the number of receptor cells (3). However, the pit is narrower and the peg smaller, the hair wall is not as uniform in its thickness, and the 3 dendrites are not as highly branched and tightly packed in the dendritic sheath compared with those of the large s. coeloconica.

The small s. coeloconica (Figs 20-22) are no-pore (poreless) sensilla with inflexible sockets and an ecdysial pore at the tip of the peg. They contain 3 receptor cells with 2 unbranched dendrites reaching up to the tip, and 1 dendrite reaching to the base of the peg. The latter dendrite wraps around the 2 other ones.

The s. campaniformia have the typical fine structure of a cuticular dome with one dendrite attached in the center. At the inner part of the segment other sensilla are found, which have one dendrite that distally contains a tubular body (Fig. 14).

\section{Electrophysiological recordings from sensilla coeloconica}

The number of successful recordings was limited. Besides several short recording series, in only one preparation could all 50 stimulus compounds be tested at least once. These are, however, the first and only data available for these animals, and despite their limitations they prove the olfactory function of these sensilla in principle (Table 1; Fig. 23). The data gained from this one sensillum appear reliable because several compounds could be tested repetitively, and the recordings were evaluated only as long as the responses to these reference substances were consistent. In addition, this one recording series allows some conclusions concerning the specificity of the receptor cells. Out of the set of 50 olfactory stimulus compounds, only the cyclic terpenoids induced responses from the receptor cells, which were very likely situated in the large s. coeloconica.

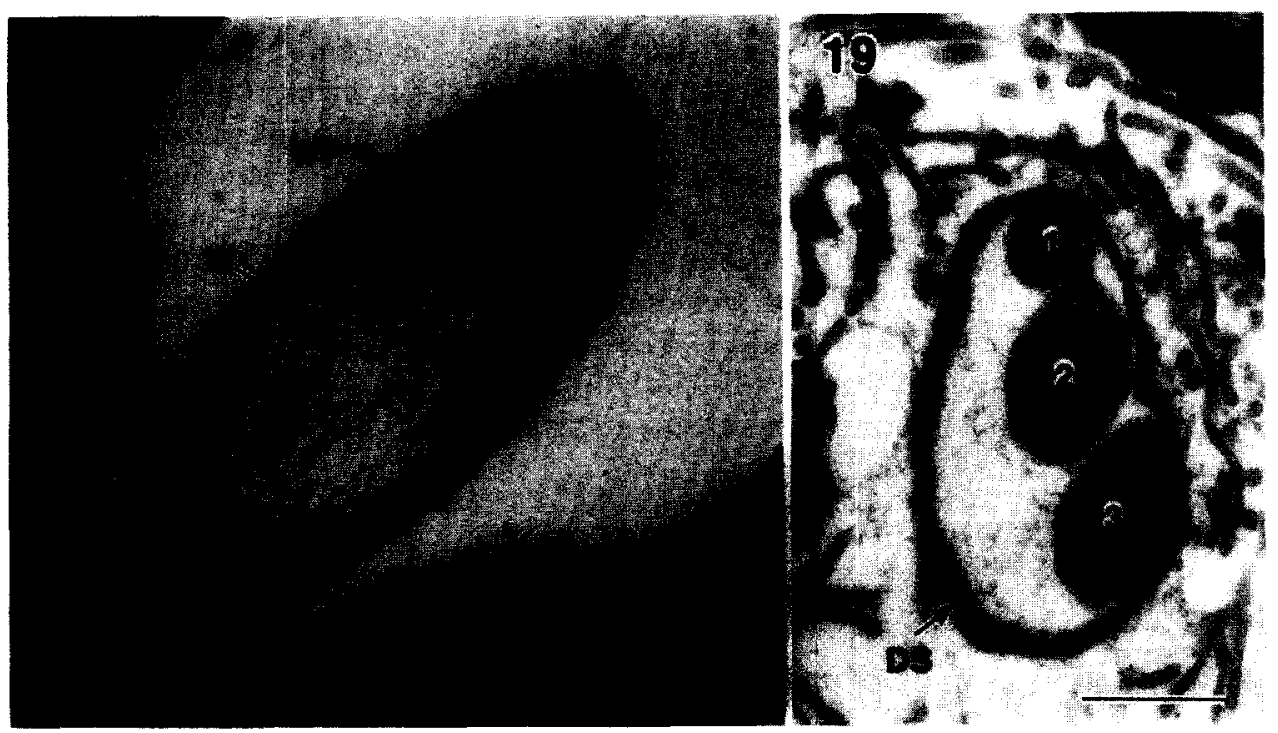

FIGs 18; 19. Medium-sized sensillum coeloconicum on flagellar segment 1 of $M$. cassini. Transmission electron micrographs. $\mathrm{Bar}=1 \mu \mathrm{m} . \mathrm{D}=$ dendritic branches; $\mathrm{DS}=$ dendritic sheath; $\mathrm{W}=$ hair wall; $\mathbf{W P}=$ wall pore; $1,2,3=$ dendrites of receptor cells $1,2,3$. FIG. 18. Oblique section of peg, showing wall pores.

Fig. 19. Cross-section of dendrites with dendritic sheath inside epidermis below peg. 


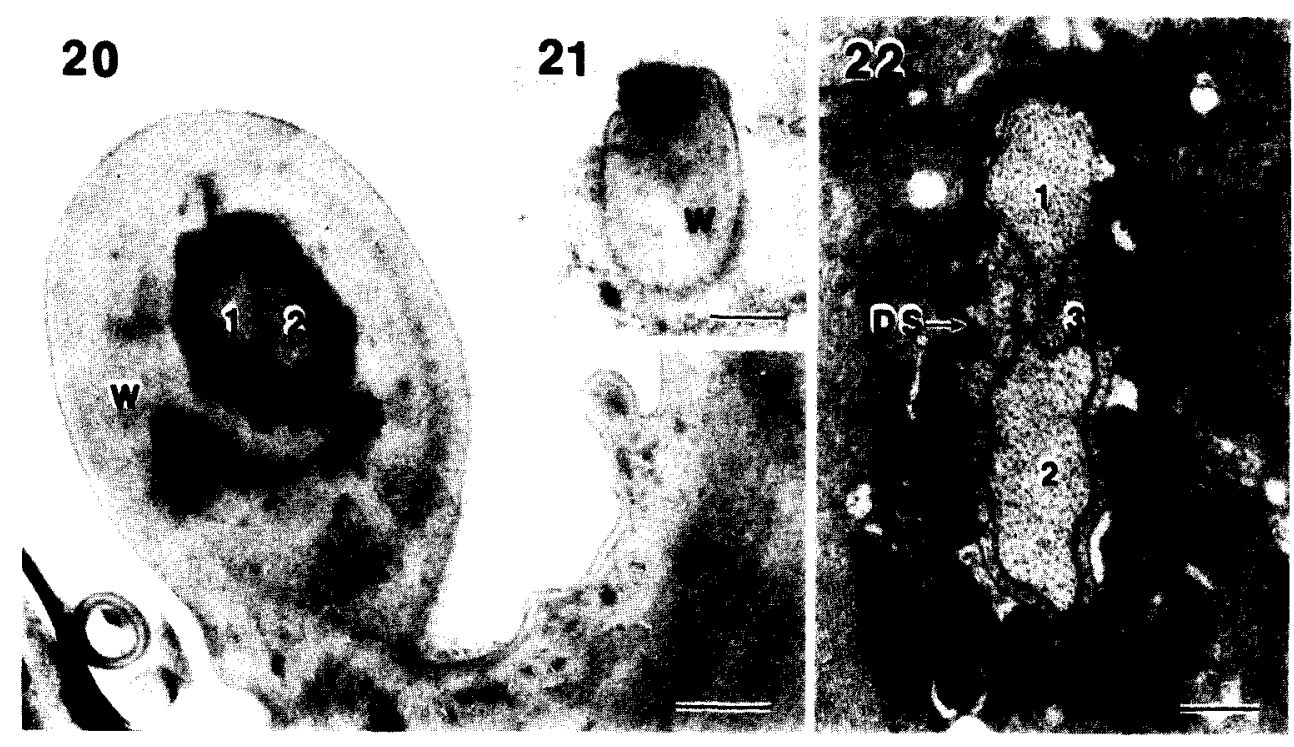

Figs 20-22. Small sensillum coeloconicum on flagellar segment 1 of $\boldsymbol{M}$. cassini. Transmission electron micrographs. Bar $=0.5 \mu \mathrm{m}$. DS = dendritic sheath; $W=$ hair wall; $1,2,3=$ dendrites of receptor cells $1,2,3$.

FIG. 20. Transverse section in distal region of peg.

Fig. 21. Ecdysial pore at tip, detail.

FIG. 22. Cross-section of dendrites with dendritic sheath inside epidermis below peg.

Identified only by nerve-impulse amplitudes, we believe that the 3 characteristic amplitudes found derive from 3 separate receptor cells in one sensillum. Based on impulse amplitudes, we label the cells as "large-spiking", "medium-spiking" and "smallspiking" (Fig. 23). Their reaction spectra are different but highly overlapping. For example, pulegone is a good stimulus for all 3 cells, but 3 -methyl-2-heptanone elicits a high response only in the "medium-spiking" cell. The response to iso-pulegol as one effective alcohol is high in the "medium-spiking" and "small-spiking" but low in the "large-spiking" cell (Table 1). In summary, the receptor cells differ by a graded selectivity to structural variations of the stimulus compounds, i.e. changes in positions and types of double bonds (cf. Table 1: $\alpha, \beta$-thujone and $\beta$-pinene, or pulegone and limonene, or coumarin and benzyl formate). In all sensilla tested, changes in $\mathrm{CO}_{2}$ or stimuli of other modalities like heat and moisture induced neither excitation nor inhibition of spontaneous activity.

\section{DISCUSSION}

\section{Structural peculiarities of the antenna}

The antennae of cicadas generally are proportionately stouter and shorter, their pedicels less differentiated, and their flagella less completely stylate or bristle-like than those of most other auchenorrhynchous homopterans. In $M$. cassini only the 3 joints between the head and scape, scape and pedicel, and pedicel and flagellar segment 1 allow active movement. The antennae are relatively small, compared with the body size of the 


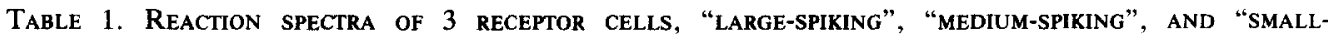
SPIKING" CELL, DISTINGUISHED BY IMPULSE AMPLITUDES; DATA FROM ONE SERIES OF EXTRACELLULAR RECORDINGS FROM A SINGLE SENSILLUM COELOCONICUM OF A FEMALE ANTENNA

\begin{tabular}{|c|c|c|c|c|}
\hline Vap & Stimulus & "Large-spiking" & "Medium-spiking" & "Small-spiking" \\
\hline & Aldehydes & & & \\
\hline 8.9 & Benzaldehyde & ++ & ++++ & +++ \\
\hline 0.7 & Anisealdehyde & + & ++ & +++ \\
\hline 1.4 & Citral & 0 & + & 0 \\
\hline \multirow[t]{2}{*}{0.6} & Cinnamon aldehyde & 0 & 0 & 0 \\
\hline & Alcohols & & & \\
\hline 2.6 & Iso-pulegol & + & ++++ & +++ \\
\hline 3.3 & Guajacol & + & ++++ & ++++ \\
\hline 2.2 & Terpineol & + & ++++ & +++ \\
\hline 3.3 & Benzyl alcohol & + & +++ & ++ \\
\hline 1.0 & Iso-eugenol & 0 & + & + \\
\hline 2.6 & Menthol & 0 & + & 0 \\
\hline 5.0 & Linalool & 0 & 0 & 0 \\
\hline 10.0 & 2-Octanol & 0 & 0 & 0 \\
\hline 1.8 & Citronellol & 0 & 0 & 0 \\
\hline 0.6 & Eugenol & 0 & 0 & 0 \\
\hline \multirow[t]{2}{*}{1.4} & Geraniol & 0 & 0 & 0 \\
\hline & Acids & & & \\
\hline 36.0 & Acrylic acid & ++ & ++ & ++++ \\
\hline 15.0 & Methyl acrylic acid & 0 & 0 & 0 \\
\hline \multirow[t]{2}{*}{67.0} & Benzoic acid & 0 & 0 & 0 \\
\hline & Esters & & & \\
\hline 4.3 & Methyl benzoate & + & +++ & 0 \\
\hline 4.2 & Benzyl formate & ++ & +++ & ++ \\
\hline \multirow[t]{2}{*}{2.6} & Ethyl benzoate & ++ & ++ & + \\
\hline & Ketones & & & \\
\hline 4.0 & $\alpha, \beta$-Thujone & +++ & +++++ & 0 \\
\hline 1.7 & Pulegone & +++ & ++++ & ++++ \\
\hline 20.0 & Cyclohexanone & ++++ & ++++ & ++ \\
\hline 100.0 & 3-Methyl-2-heptanone & + & $++t+$ & 0 \\
\hline 1.3 & Carvone & +++ & ++++ & +++ \\
\hline \multirow[t]{2}{*}{160.0} & 3-Methyl-3-butene-2-one & ++ & +++ & +++ \\
\hline & Hydrocarbons & & & \\
\hline 14.0 & $\beta$-Pinene & ++ & +++++ & ++++ \\
\hline 1.7 & $+/-$ Camphene & +++ & ++++ & ++++ \\
\hline 9.6 & Limonene & ++ & +++++ & +++ \\
\hline 0.1 & Coumarin & + & +++ & + \\
\hline 9.6 & p-Cymol & 0 & 0 & 0 \\
\hline 290.0 & Cyclohexene & 0 & 0 & + \\
\hline
\end{tabular}

Responses are quantified as: $0=$ no response to stimulus; $+<5 ;++5$ to $<10 ;+++10$ to $<20 ;++++20$ to $<30 ;+++++30$ to $<40 ;++++++\geqslant 40$ impulses/sec during stimulus. Vap = stimulus intensity in $\left(\right.$ molecules $\left./ \mathrm{cm}^{3}\right) \times 10^{-15}$ at an air velocity of $1 \mathrm{~m} / \mathrm{sec}$. 

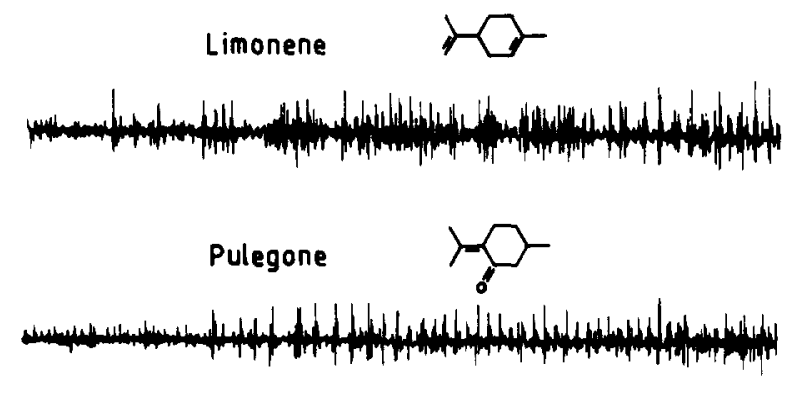

$$
\text { a.ß-Thujone } P
$$

(1)
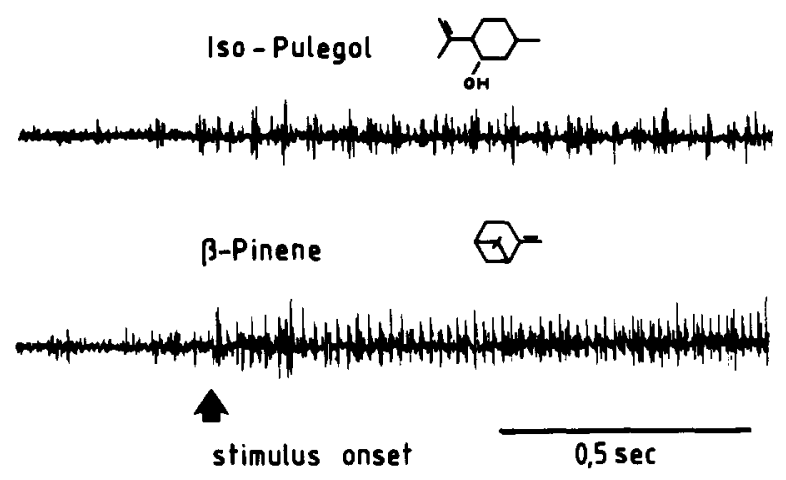

Fig. 23. Electrophysiological recordings of responses of one s. coeloconicum to stimulation with different chemical compounds (cf. Table 1). Stimulus duration $2 \mathrm{sec}$.

animal. Whereas head size differs clearly between the sexes, the length of flagellar segment 1 does not. In addition, no sex-specific difference is found in the number of $\mathrm{s}$. coeloconica forming the ventrolateral sensillum field, the most obvious feature on flagellar segment 1 .

The strongly tapering and distally shriveled antennae of adult cicadas appear to be reduced in shape and condition compared with the well-developed antennae of nymphs. As described by Lew (1960) for $M$. septendecim, both stages have the same number of 7 segments in all 3 species, but in the nymphs the borders between the distal flagellar segments are more distinct, and the flagellar segment 5 is frequently constricted near the middle giving the strong impression of additional segmentation; the cuticle of the nymphal antenna is not shriveled, and all segments bear large numbers of at least long hair sensilla. It seems worthwhile to investigate whether the antennae are of different or greater importance in the long subterranean life of the nymphs than in the short adult life above ground.

2. Presumed functions of the antennal sensilla

Rimmed pores and small plates with little knobs as on scape and pedicel are also found 
all over the head capsule, but especially on the vertex (Klein and Bock, unpublished). They are presumed to secrete waxes (Locke, 1959, 1960; Foldi, 1983), which is very common in other Homoptera and Hemiptera. In other insects, the rims of the pores ("cylinders") serve to include air in the threads during molding giving rise to the name "micro-macaroni" for such threads (Pope, 1984). Based on comparative studies, it is possible to ascribe presumed functions to the different types of the antennal sensilla. The sensilla on scape and pedicel mostly stand inclined relative to the cuticular surface, they have flexible sockets, and very likely are mechanoreceptive hair sensilla (McIver, 1975; Keil and Steinbrecht, 1984). Smaller sensilla, situated in pits or on the surface, could be chemo-, thermo-, and hygroreceptive (Stürckow, 1970; Altner and Prillinger, 1980; Steinbrecht, 1984), as well as mechanoreceptive hair sensilla. The upright hairs could be gustatory sensilla, which often stand at right angles to the cuticular surface (cf. Fig. 5; Klein, 1981). The s. campaniformia are well known mechanoreceptive structures (McIver, 1975; Keil and Steinbrecht, 1984).

The fine structure of the dendrites of the small s. coeloconica corresponds to the classical "triad" of 2 thermo- and 1 hygroreceptor cell (Altner et al., 1983; Steinbrecht, 1984; Altner and Loftus, 1985). Sensilla with both temperature and humidity receptor cells usually stand singly and occur only in very few numbers (Chapman, 1982). On the antennae of $M$. cassini, however, a fairly high number of small s. coeloconica are lined up in a row along the outer ventral side of flagellar segment 1.

The large and the medium-sized s. coeloconica are far more numerous than the small ones. Their spatial arrangement in a dense field might have functional significance for enhanced chemoreceptive sensitivity. They are positioned in a way suited to easily receive airborne odors (cf. Fig. 1). As early as 1890 , large and small s. coeloconica on the flagellar segments of the antennae of $M$. septendecim were mentioned by Hansen (1890), and in 1909 Berlese proposed an olfactory function for them "although without any experimental evidence in support of this view" (Myers, 1928). Our investigation of their fine structure, showing wall pores with pore tubules, now presents strong evidence for an olfactory function. This is established by our electrophysiological recordings, even though the number of experiments is limited. It is very probable that we hit mainly large s. coeloconica with our recording electrode because of their larger size and higher number. The individual differences among the 3 receptor cells in their response magnitudes to structural variations of the stimulus compounds are in accordance with results from other studies of structure-activity relationships, for example, in the olfactory sensilla of moth antennae, the stimulus intensities leading to equivalent responses differed by a factor of 10 to 100 (Kafka, 1987). Far more data are necessary to analyze the coding properties of the receptor cells of the antennal sensilla of these cicadas in detail. Some conclusions about their biological role, however, may now be drawn.

\section{The behavioral role of olfaction in Magicicadas}

The established effective olfactory stimuli for the antennal sensilla of $M$. cassini are cyclic terpenoids, which are common in differing proportions in most plants (Seigler, 1981). Terpenoids function as aggregation and sex attractants in bees and bark beetles, as stimulators of reproductive activity in desert locusts, moths, and butterflies, as feeding stimulants in weevils, as feeding repellents to many insects in many plant groups (Rodriguez and Levin, 1976). In cicadas, antennal olfaction could provide early information in host plant selection over some distance, which could be followed by 
subsequent contact chemical signals, perceived by sensilla on the beak or ovipositor touching the substrate (Klein et al., 1987). The stimulating terpenoids occur especially in herbs and flowers of the Labiatae (pulegone; Seigler, 1981) and in coniferous trees of the Pinaceae (limonene, pinene, thujone; Seigler, 1981). In the northeastern American Labiatae, there are no woody shrubs or trees with small branches, suitable for feeding or oviposition. In the Pinaceae, the hatching success of eggs is reduced by resin secretion preventing eggs from hatching or trapping hatchlings in eggnests (White et al., 1982). Olfaction of substances like pinene might suggest that the perception of repellents guides the initial choice of host plants in Magicicada species. However, adults feed or oviposit readily on the conifer Juniperus viriginiana (Moore, unpublished), Magicicada septendecim accepts a terpenoid producing Aster spp. for feeding but not for oviposition (Maier, 1982). The tropical American cicada Fidicina mannifera aggregates disproportionately on trunks of an uncommon, terpenoid-producing tree species (Rutaceae; Johnson and Foster, 1986), although it is not restricted to that host or that habitat. Therefore, we still do not yet know whether the behavioral responses to the cyclic terpenoids used would be repellent, attractant or neutral.

We are mindful that there could be other effective stimuli for these antennal sensilla, as well as sensilla with other chemical specificities not yet tested, functional in behavioral contexts other than host plant selection. There is, as yet, little hint of a contribution of chemical signals in the sexual behavior; long range cues in species recognition, aggregation and pair formation are primarily acoustic and visual (Alexander and Moore, 1958, 1962; for a more intense discussion of behavioral role of chemoreception in periodical cicadas, see Klein et al., 1988). Clearly, further behavioral and physiological studies of all the participating sense organs are needed to reveal the kind of specificity of their chemical senses and their potential roles in the inter-individual and host plant associations of Magicicada species.

Acknowledgements - We are indebted to Franz Huber for his generous support of the work and his continuous encouragement, and to him and Theo Weber for many valuable discussions. Thanks for critical reading of the manuscript and helpful comments are due to Helmut Altner, Thomas A. Keil and Rudolf A. Steinbrecht.

\section{REFERENCES}

Alexander, R. D. and T. E. Moore. 1958. Studies on the acoustical behavior of seventeen-year cicadas (Homoptera : Cicadidae : Magicicada). Ohio J. Sci. 58: 107-27.

Alexander, R. D. and T. E. Moore. 1962. The evolutionary relationships of 17-year and 13-year cicadas, and three new species (Homoptera : Cicadidae : Magicicada). Misc. Publ. Mus. Zool. Univ. Michigan 121: $5-9$.

Altner, H. and L. Prillinger. 1980. Ultrastructure of invertebrate chemo-, thermo- and hygroreceptors and its functional significance. Int. Rev. Cytol. 67: 69-139.

Altner, H., L. Schaller-Selzer, H. Stetter and I. Wohlrab. 1983. Poreless sensilla with inflexible sockets. A comparative study of a fundamental type of insect sensilla probably comprising thermoand hygroreceptors. Cell Tissue Res. 234: 279-307.

Altner, H. and R. Lofrus. 1985. Ultrastructure and function of insect thermo- and hygroreceptors. Annu. Rev. Entomol. 30: 273-95.

Bock, C. 1987. A quick and simple method for preparing soft insect tissues for scanning electron microscopy using Carnoy and Hexamethyldisilazane. Beitr. Elektronenmikroskop. Direktabb. Oberfl. 20: 209-14.

Chapman, R. F. 1982. Chemoreception: The significance of receptor numbers. Adv. Insect Physiol. 16: $247-355$.

DyBas, H. S. and M. Lloyd. 1962. Isolation by habitats in two synchronized species of periodical cicadas (Homoptera : Cicadidae : Magicicada). Ecology 43: 444-59. 
Dybas, H. S. and M. Lloyd. 1974. The habitats of seventeen-year periodical cicadas (Homoptera : Cicadidae : Magicicada spp.). Ecol. Monogr. 44: 279-324.

FoLDI, I. 1983. Ultrastructure comparée des glandes tégumentaires des cochenilles diaspines (Homoptera : Diaspididae). Int. J. Insect Morphol. Embryol. 12: 339-54.

Hansen, H. J. 1890. Gamle og nye Hovedmomenter til Cicadariernes. Morphol. Syst. Entomol. Tidskrift 11: 19-76.

Hayat, M. A. 1978. Introduction to Biological Scanning Electron Microscopy. University Park Press, Baltimore.

Hoppensteadt, F. C. and J. B. KEller. 1976. Synchronization of periodical cicada emergences. Science (Wash., D.C.) 194: 335-37.

Johnson, L. K. and R. B. Foster. 1986. Association of large Homoptera (Fulgoroidae and Cicadidae) in their trees in a tropical forest. J. Kansas Entomol. Soc. 59: 415-22.

Kafka, W. A. 1970. Molekulare Wechselwirkungen bei der Erregung einzelner Riechzellen. Z. Vgl. Physiol. 70: $105-43$.

KAFKA, W. A. 1987. Similarity of reaction spectra and odor discrimination: single receptor-cell recordings in Antheraea polyphemus. J. Comp. Physiol. A. 161: 867-80.

KARBAN, R. 1982. Increased reproductive success at high densities and predator satiation for periodical cicadas. Ecology 63: 321-28.

KeIL, T. A. and R. A. Steinbrecht. 1984. Mechanosensitive and olfactory sensilla of insects, pp. 477-516. In R. C. KInG and H. AkaI. (eds) Insect Ultrastructure. Vol 2. Plenum Press, New York.

KLEIN, U. 1981. Sensilla on the cricket palp. Fine structure and spatial organization. Cell Tissue Res. 219: 229-52.

Klein, U., C. Bock, W. A. Kafka and T. E. Moore. 1987. Sensory equipment of the 17-year cicada: structural survey and physiological evidence for olfaction. Chem. Sens. 12: 211.

Klein, U., C. Bock, W. A. KAFKA and T. E. Moore. 1988. Olfactory sensilla on the antennae of Magicicada cassini (Fisher) (Homoptera, Cicadidae): structure, function and possible behavioral role. 6th Auchenorrhyncha Meeting, Turin, Proc. Auchenorrhyncha Soc. (in press).

Kramer, S. 1950. The morphology and phylogeny of auchenorrhynchous Homoptera. Insecta. Illinois Biol. Monogr. 20: 1-109.

LEw, G. L. 1960. The external morphology of the last instar nymph of Magicicada septendecim (L.) (Hemiptera : Homoptera). Entomol. Amer. 39: 101-79.

Lloyd, M. 1984. Periodical cicadas. Antenna 8: 79-91.

Lloyd, M. and H. S. Dybas. 1966a. The periodical cicada problem. I. Population ecology, Evolution 20: 133-49.

Lloyd, M. and H. S. Dybas. 1966b. The periodical cicada problem. II. Evolution. Evolution 20: 466-505.

Locke, M. 1959. Secretion of wax through the cuticle of insects. Nature (Lond.) 184: 1967.

LoCKe, M. 1960. The cuticle and wax secretion of Calpodes ethlius (Lepidoptera, Hesperidae). Q. J. Microsc. Sci. 101: 333-38.

MAIER, C. T. 1982. Observations on the seventeen-year periodical cicada, Magicicada septendecim. (Homoptera : Cicadidae). Ann. Entomol. Soc. Amer. 75: 14-23.

MCIver, S. 1975. Structure of cuticular mechanoreceptors of arthropods. Annu. Rev. Entomol. 20: 381-97.

Myers, J. G. 1928. The morphology of the Cicadidae (Homoptera), Proc. Zool. Soc., Lond. 25: 365-472.

PoPE, R. D. 1984. Visible insect waxes: form, function and classification. Antenna 8: 4-8.

Rodriguez, E. and D. A. LEVIN. 1976. Biochemical parallelism of repellents and attractants in higher plants and arthropods, pp. 214-70. In J. W. WALlace and R. L. MANSELL (eds) Biochemical Interaction between Plants and Insects. Recent Advances in Phytochemistry. Vol. 10. Plenum Press, New York.

SEIGler, D. S. 1981. Secondary metabolites and plant systematics, pp. 139-76. In E. E. ConN (ed.) The Biochemistry of Plants. A Comprehensive Treatise. Secondary Plant Products. Vol. 7. Academic Press, New York.

STÜrCKow, B. 1970. Responses of olfactory and gustatory receptor cells in insects. Adv. Chemorec. 1: 107-59. Snodgrass, R. E. 1927. The head and mouth parts of the cicada. Proc. Entomol. Soc., Wash. 29: 1-16.

Steinbrecht, R. A. 1984. Chemo-, thermo-, and hygroreceptors, pp. 523-53. In J. Bereiter-HahN, A. G. Matoltsy and K. S. Richards (eds.) Biology of the Integument. Vol. 1, Invertebrates. Springer, Berlin, Heidelberg.

White, J. 1980. Resource partitioning by ovipositioning cicadas. Amer. Natur. 115: 1-28.

White, J., M. Lloyd and R. KaRBAN. 1982. Why don't periodical cicadas normally live in coniferous forests? Environ. Entomol. 11: 475-82. 